\title{
Corrigendum: Expertise-Related Differences in Wrist Muscle Co-contraction in Drummers
}

\author{
Scott Beveridge ${ }^{1 *}$, Steffen A. Herff ${ }^{2,3}$, Bryony Buck ${ }^{1}$, Gerard Breaden Madden ${ }^{1}$ and \\ Hans-Christian Jabusch ${ }^{1}$ \\ ${ }^{1}$ Institut für Musikermedizin (IMM), Hochschule für Musik Carl Maria von Weber, Dresden, Germany, ${ }^{2}$ Digital and Cognitive \\ Musicology Lab (DCML), École Polytechnique Fédérale de Lausanne (EPFL), Lausanne, Switzerland, ${ }^{3}$ Music Cognition and \\ Action Research Group (MCA), MARCS Institute for Brain, Behaviour \& Development, Western Sydney University (WSU), \\ Sydney, NSW, Australia
}

Keywords: electromyography, drummers, expertise, practice, motor control, coordination abilities, musicians, muscle co-contraction

\section{A Corrigendum on}

Expertise-Related Differences in Wrist Muscle Co-contraction in Drummers

OPEN ACCESS

Edited by:

Andrea Schiavio,

University of Graz, Austria

Reviewed by:

Matthew Rodger,

Queen's University Belfast,

United Kingdom

*Correspondence:

Scott Beveridge

scottwbeveridge@gmail.com

Specialty section: This article was submitted to Performance Science, a section of the journal

Frontiers in Psychology

Received: 07 May 2021

Accepted: 07 June 2021

Published: 23 July 2021

Citation:

Beveridge S, Herff SA, Buck B, Madden GB and Jabusch H-C (2021)

Corrigendum: Expertise-Related

Differences in Wrist Muscle

Co-contraction in Drummers.

Front. Psychol. 12:706228.

doi: 10.3389/fpsyg.2021.706228 by Beveridge, S., Herff, S. A., Buck, B., Madden, G. B., and Jabusch, H.-C. (2020). Front. Psychol. 11:1360. doi: 10.3389/fpsyg.2020.01360

In the original article there were several errors in the text.

In the original article we stated that:

"In the early learning stages of performing simple arm actions, such as pointing or reaching, the co-contraction of antagonistic muscle pairs is commonly observed and improves movement accuracy (Fitts, 1954; Gribble et al., 2003; Yang et al., 2007; Wong et al., 2009).”

The references (Fitts, 1954) and (Yang et al., 2007) do not address specifically muscle co-contraction and have been removed.

A correction has been made to Introduction, Paragraph 2. The corrected paragraph is shown below.

Whilst energy inefficient, co-contraction can have beneficial effects during skill acquisition. In the early learning stages of performing simple arm actions, such as pointing or reaching, the co-contraction of antagonistic muscle pairs is commonly observed and improves movement accuracy (Gribble et al., 2003; Wong et al., 2009). As skill increases, this co-contraction decreases while accuracy remains high (Bernstein, 1967; Moore and Marteniuk, 1986; Thoroughman and Shadmehr, 1999; Osu et al., 2002; Gribble et al., 2003). This reduction in muscle co-contraction has also been reported during the learning of music-related movements, including drumming (Fujii et al., 2009a,b; Verrel et al., 2013). Specifically, Fujii et al. (2009a,b) report pronounced reciprocal contractions of antagonistic muscle pairs acting on the wrist: the flexor carpi ulnaris (FCU) and the extensor carpi radialis (ECR). In addition, Fujii observed a shorter decline in muscle activity and a smaller variability of activation time of the wrist flexor muscle (flexor carpi ulnaris) in drummers when compared to non-drummers. Here, we aim to shed further light on expertise-related changes in muscle activation patterns during repetitive drumming using surface electromyography (sEMG; sEMG measures electrical activity on the surface of the skin that reflects activation of the underlying muscle groups). 
Next, in the original article we stated that:

"The pattern of motion employed and the characteristics of firing of muscles within the upper limbs was seen to increase the smoothness and accuracy of the striking motion executed (Gribble et al., 2003; Aluru et al., 2014)".

The inclusion of this sentence is not within the context of the paragraph (musical movements) and has therefore been removed.

A correction has been made to Introduction, Paragraph 3. The corrected paragraph is shown below.

Patterns of muscle activation can also be indicative of task difficulty. Chong and colleagues asked non-musicians to play hand percussion and showed that sEMG amplitude rise increased in response to increased playing tempo (Chong et al., 2015). Similar results were observed during keyboard playing, with sEMG activity rising in specific forearm muscles in response to increased tempo (Chong et al., 2015). Here, we also explore the role of tempo in muscle activity patterns, and how tempoinduced task difficulty may interact with expertise.

Additionally, in the original article we stated that:

"Drumming studies have revealed that, in addition to precise control of limb movements, control of the end-effector plays a major factor in accuracy as well as influencing timbral aspects of the performance (Osu et al., 2002; Gribble et al., 2003; Dahl and Altenmüller, 2008; Fujisawa and Miura, 2010; Aluru et al., 2014).”

The inclusion of the references (Osu et al., 2002), (Gribble et al., 2003), and (Aluru et al., 2014) fall outside the scope of this paragraph and have been removed.

A correction has been made to Introduction, Paragraph 6. The corrected paragraph is shown below.

Drumming studies have revealed that, in addition to precise control of limb movements, control of the end-effector plays a major factor in accuracy as well as influencing timbral aspects of the performance (Dahl and Altenmüller, 2008; Fujisawa and Miura, 2010). Drum strokes can be considered discrete actions, but more often linked together as a continuous motion. This allows for preparatory actions in the stick rebound phase that improve stick control (Dahl, 2011). Stick control is an important determinant of co-contraction (Dahl and Altenmüller, 2008;

\section{REFERENCES}

Aluru, V., Lu, Y., Leung, A., Verghese, J., and Raghavan, P. (2014). Effect of auditory constraints on motor performance depends on stage of recovery post-stroke. Front. Neurol. 5:152. doi: 10.3389/fneur.2014.00106

Bernstein, N. A. (1967). The co-ordination and Regulation of Movements. Oxford, UK: Pergamon Press Ltd.

Chong, H. J., Kim, S. J., Lee, E. K., and Yoo, G. E. (2015). Analysis of surface EMG activation in hand percussion playing depending on the grasping type and the tempo. J. Exerc. Rehabil. 11:228. doi: 10.12965/jer.150216

Dahl, S. (2011). Striking movements: a survey of motion analysis of percussionists. Acoust. Sci. Technol. 32, 168-173. doi: 10.1250/ast.32.168

Dahl, S., and Altenmüller, E. (2008). Motor control in drumming: influence of movement pattern on contact force and sound characteristics. J. Acoust. Soc. Am. 123:3122. doi: 10.1121/1.2933043

Dounskaia, N., Swinnen, S., Walter, C., Spaepen, A., and Verschueren, S. (1998). Hierarchical control of different elbow-wrist coordination patterns. Exp. Brain Res. 121, 239-254. doi: 10.1007/s002210050457
Fujisawa and Miura, 2010), which, in turn, has been connected to varying levels performance accuracy. In a study examining playing strategy and performance experience between amateur and non-drummers, Fujisawa and colleagues found that less skilled drummers played with higher levels of muscular strain (co-contraction) (Fujisawa and Miura, 2010). Furthermore, Kawakami and colleagues demonstrated that the sound and energy of the performance during repeated striking was directly related to the acceleration control of the stick both before and after each hit (Kawakami et al., 2008). Similar variations have been found between striking impulse and tempo control strategies of pianists. The use of such strategies influenced not only the tempo but also the tone of the notes (Furuya and Kinoshita, 2007).

Lastly, in the original article we stated that:

"This may have prevented players (especially those with lower expertise) from fulfilling the task demands resulting in reduced performance accuracy (Dounskaia et al., 1998; Fujii et al., 2011)."

The inclusion of (Dounskaia et al., 1998) does not fall within the context of musical movements.

A correction has been made to section 4.2.2. Performance and Tempo, Paragraph 1.

Our findings are consistent with previous studies that report performance of expert drummers (measured in CV-ITI) to range between 2 and 5\% of an eighth note (Madison, 2000). However, across all drummers, expertise, and exercises we observed a significant drop in performance as tempo increased. A possible explanation for this is that we are reaching the biomechanical limits for rapid upper arm movement. The maximum tapping frequency of motor effectors are reported to be between 5 and $7 \mathrm{~Hz}$, corresponding to ITIs of $150-200 \mathrm{~ms}$. The highest tempo in the present study is 400 HPM, which represents an ITI of $150 \mathrm{~ms}$. This may have prevented players (especially those with lower expertise) from fulfilling the task demands resulting in reduced performance accuracy (Fujii et al., 2011).

The authors apologize for these errors and state that they do not change the scientific conclusions of the article in any way. The original article has been updated.

Fitts, P. M. (1954). The information capacity of the human motor system in controlling the amplitude of movement. J. Exp. Psychol. 47:381. doi: $10.1037 /$ h0055392

Fujii, S., Hirashima, M., Kudo, K., Ohtsuki, T., Nakamura, Y., and Oda, S. (2011). Synchronization error of drum kit playing with a metronome at different tempi by professional drummers. Mus. Percept. 28, 491-503. doi: $10.1525 / \mathrm{mp} .2011 .28 .5 .491$

Fujii, S., Kudo, K., Ohtsuki, T., and Oda, S. (2009a). Tapping performance and underlying wrist muscle activity of non-drummers, drummers, and the world's fastest drummer. Neurosci. Lett. 459, 69-73. doi: 10.1016/j.neulet.2009. 04.055

Fujii, S., Kudo, K., Shinya, M., Ohtsuki, T., and Oda, S. (2009b). Wrist muscle activity during rapid unimanual tapping with a drumstick in drummers and nondrummers. Motor Control 13, 237-250. doi: 10.1123/mcj.13. 3.237

Fujisawa, T., and Miura, M. (2010). Investigating a playing strategy for drumming using surface electromyograms. Acoust. Sci. Technol. 31, 300-303. doi: 10.1250/ast.31.300 
Furuya, S., and Kinoshita, H. (2007). Roles of proximal-to-distal sequential organization of the upper limb segments in striking the keys by expert pianists. Neurosci. Lett. 421, 264-269. doi: 10.1016/j.neulet.2007.05.051

Gribble, P. L., Mullin, L. I., Cothros, N., and Mattar, A. (2003). Role of cocontraction in arm movement accuracy. J. Neurophysiol. 89, 2396-2405. doi: 10.1152/jn.01020.2002

Kawakami, H., Mito, Y., Watanuma, R., and Marumo, M. (2008). Analysis of drum player's motion. J. Acoust. Soc. Am. 123:3799. doi: 10.1121/1.2935483

Madison, G. (2000). "On the nature of variability in isochronous serial interval production," in Rhythm Perception and Production, eds P. Desain and L. Windsor (Lisse: Swets and Zeitlinger), 95-113.

Moore, S. P., and Marteniuk, R. (1986). Kinematic and electromyographic changes that occur as a function of learning a time-constrained aiming task. J. Motor Behav. 18, 397-426. doi: 10.1080/00222895.1986.10735388

Osu, R., Franklin, D. W., Kato, H., Gomi, H., Domen, K., Yoshioka, T., et al. (2002). Short-and long-term changes in joint co-contraction associated with motor learning as revealed from surface EMG. J. Neurophysiol. 88, 991-1004. doi: 10.1152/jn.2002.88.2.991

Thoroughman, K. A., and Shadmehr, R. (1999). Electromyographic correlates of learning an internal model of reaching movements. J. Neurosci. 19, 8573-8588. doi: 10.1523/JNEUROSCI.19-19-08573.1999

Verrel, J., Pologe, S., Manselle, W., Lindenberger, U., and Woollacott, M. (2013). Exploiting biomechanical degrees of freedom for fast and accurate changes in movement direction: coordination underlying quick bow reversals during continuous cello bowing. Front. Hum. Neurosci. 7:157 doi: 10.3389/fnhum.2013.00157

Wong, J., Wilson, E. T., Malfait, N., and Gribble, P. L. (2009). Limb stiffness is modulated with spatial accuracy requirements during movement in the absence of destabilizing forces. J. Neurophysiol. 101, 1542-1549. doi: 10.1152/jn.91188.2008

Yang, J.-F., Scholz, J. P., and Latash, M. L. (2007). The role of kinematic redundancy in adaptation of reaching. Exp. Brain Res. 176, 54-69. doi: 10.1007/s00221-006-0602-8

Publisher's Note: All claims expressed in this article are solely those of the authors and do not necessarily represent those of their affiliated organizations, or those of the publisher, the editors and the reviewers. Any product that may be evaluated in this article, or claim that may be made by its manufacturer, is not guaranteed or endorsed by the publisher.

Copyright (c) 2021 Beveridge, Herff, Buck, Madden and Jabusch. This is an openaccess article distributed under the terms of the Creative Commons Attribution License (CC BY). The use, distribution or reproduction in other forums is permitted, provided the original author(s) and the copyright owner(s) are credited and that the original publication in this journal is cited, in accordance with accepted academic practice. No use, distribution or reproduction is permitted which does not comply with these terms. 